\title{
Right Side Congenital Diaphragmatic Hernia and Hydrops: May Not Be Lethal
}

\author{
Maha Y. Bamehriz, MD, ssc-Ped \\ Department of Pediatric, Faculty of Medicine, King Abdulaziz University \\ Jeddah, Saudi Arabia
}

\section{Correspondence}

Dr. Maha Yaslem Bamehriz

Department of Pediatric

Faculty of Medicine, King Abdulaziz University

P.O. Box 80215, Jeddah 21589

Saudi Arabia

e.M: mbamehrez@kau.edu.sa

$\begin{array}{ll}\text { Submission: } & 19 \text { Apr. } 2018 \\ \text { Accepted: } & 30 \text { Apr. } 2018\end{array}$

\section{Citation}

Bamehriz MY. Right side congenital

diaphragmatic hernia and hydrops: may not be

lethal. JKAU Med Sci 2018; 25 (2): 37-41. DOl:

10.4197/Med. 25.2.4

Copyright: $\odot$ The Author(s), YEAR. Publisher. The Journal of King Abdualziz University - Medical Sciences is an Official Publication of "King Abdulaziz University". It is an open-access article distributed under the terms of the Creative Commons Attribution Non-Commercial

License, which permit unrestricted non-commercial use, distribution, and

\begin{abstract}
Right sided congenital diaphragmatic hernia associated with hydrops is a rare event and carries a poor prognosis. We report here a case of right side diaphragmatic hernia associated with hydrops which was diagnosed antenatally and survived to discharge with good outcome.
\end{abstract}

\section{Keywords \\ Congenital diaphragmatic hernia; Right-side congenital diaphragmatic hernia; Non-immune hydrops fetalis}

\section{Introduction}

ongenital diaphragmatic hernia $(\mathrm{CDH})$ carries a high risk for neonatal mortality and morbidities ${ }^{[1]}$.

Right sided congenital diaphragmatic hernia (RT$\mathrm{CDH}$ ) with presence of the liver protruded into the chest cavity occurs less frequently than left side ${ }^{[2,3]}$, and holds a worse outcome especially when associated with fetal thoracic anomalies or hydrops. Hydrops is defined as the presence of skin and scalp edema or fluid in two or more body compartments.

\section{Case Report}

A 34-year-old, G8 P3+4 mother, was referred at 29 weeks to King Abdulaziz University Hospital for detailed ultrasound evaluation and management.
Fetal ultrasound was done in the fetomaternal unit and showed a large right side diaphragmatic hernia with a large portion of the liver protruding into the chest cavity and the heart was pushed to the left side. There was a significant hydrops with ascites, pleural effusion and hydrocele. Other organs were normal (Fig. 1). Amniotic fluid reduction was done at that time. Repeated ultrasound after three weeks showed progressive re-accumulation of fluid. Fetal echocardiogram and fetal Doppler showed normal fetal cardiac anatomy with pericardial effusion. Toxoplasma, syphilis, rubella cytomegalovirus, herpes (TORCH) serology was negative.

A male infant of $3800 \mathrm{gm}$ was delivered by cesarean section at $35+5$ weeks' gestation due to preterm labor. Apgar score was 1,5,7 at 1,5,10 minutes, respectively. On 
Right Side Congenital Diaphragmatic Hernia and Hydrops: May Not Be Lethal M.Y. Bamehriz

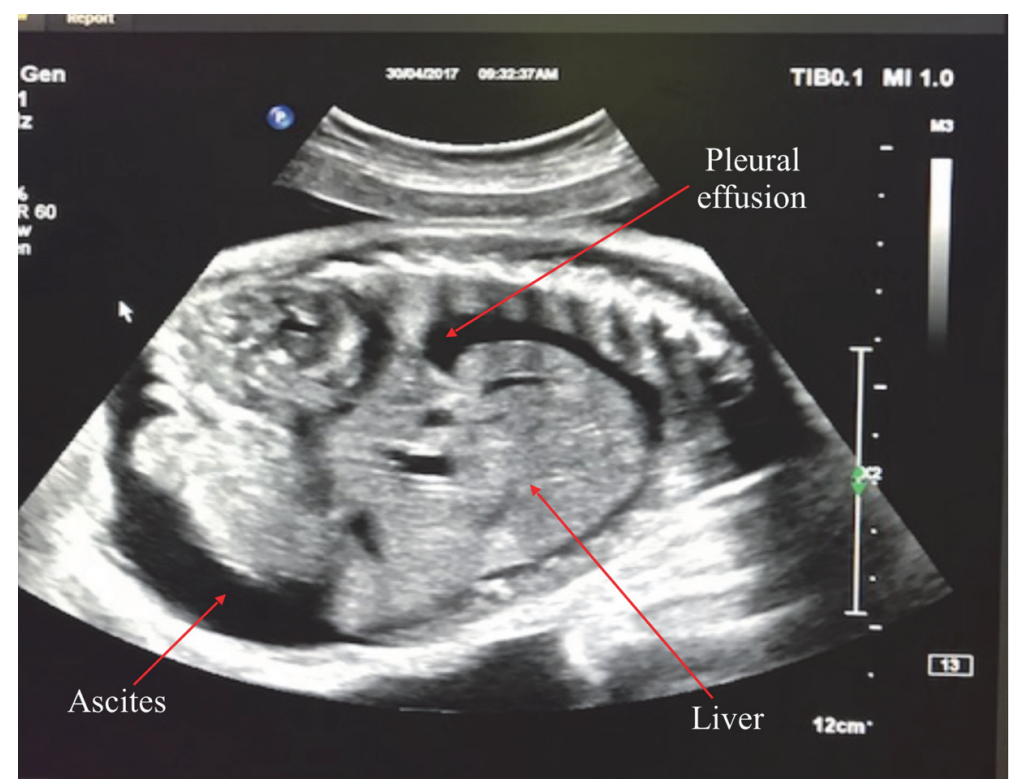

Figure 1. Fetal ultrasound showed pleural effusion, ascites and liver in the chest.



Figure 2. Chest X-ray showing right side diaphragmatic hernia.

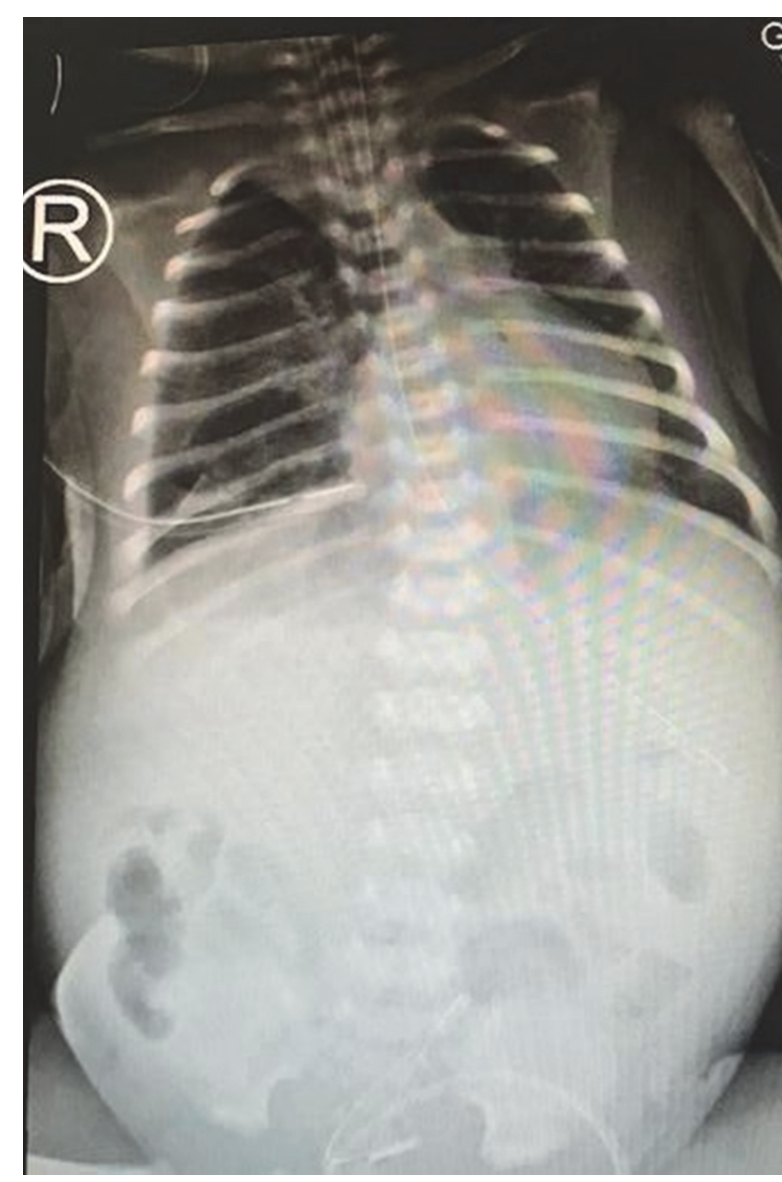

Figure 3. Chest X-ray showing postoperative right-side lung inflation. 
examination, there was generalized body edema, and no dysmorphic features suggestive of any syndromes. The initial cord gas showed pH 7.19, pCO2 68 mm Hg, and HCO3 $17.8 \mathrm{mmol} / \mathrm{L}$. He was intubated immediately after birth and transferred to neonatal intensive care unit (NICU) for further management.

In the NICU the patient required escalation of mechanical ventilation from conventional to high frequency oscillation ventilation to manage oxygenation failure. Chest X-ray confirmed the antenatal findings (Fig. 2). Echocardiogram was performed and revealed severe pulmonary hypertension, with moderately dilated right ventricle and normal function. The patient received inotropic support for systemic hypotension and Milrinone infusion of $0.5 \mathrm{mcg} / \mathrm{kg} / \mathrm{hr}$ that was increased to 0.75 $\mathrm{mcg} / \mathrm{kg} / \mathrm{hr}$, followed by Sildenafil orally for severe pulmonary hypertension. Inotropes were weaned gradually and stopped by day 3 of life, on day 6 of life patient was shifted to conventional mechanical ventilation. Milrinone was weaned off and patient was continued on sildenafil. Skin edema improved gradually. At age 24 days of life patient underwent corrective surgery where the surgeon replaced the liver back into the abdominal cavity and closed the defect with proline with no patch used. Intra-operative the antenatal diagnosis was confirmed. The operation was tolerated very well by the patient (Fig. 3). Three days' post-operatively, feeding was started, and full feeding was reached on day 50 of life. The patient was extubated to non-invasive ventilation at age 39 days. The patient was discharged home at age 63 days of life on room air and full oral feeding.

\section{Discussion}

Congenital diaphragmatic hernia $(\mathrm{CDH})$ is a defect in the diaphragm that allows the movements of abdominal organs into the thoracic cavity. The reported incidence of $\mathrm{CDH}$ is 1 in 2500-4000 live birth ${ }^{[1]}$. Right side diaphragmatic hernia (RT-CDH) occurs less frequently than Left side diaphragmatic hernia (LT$\mathrm{CDH}$ ) with an incidence ranging between 14\%-25\% of all $\mathrm{CDH}^{[2-4]}$. Prenatal diagnosis is less common in RT$\mathrm{CDH}$ compared to LT-CDH due to similar echogenicity of both liver and lung ${ }^{[2-5]}$ and late presentation.

Hydrops associated with $\mathrm{CDH}$ is a rare event. It appears that it is more common with RT-CDH and carries a poor prognosis, as presence of the liver in the thorax may obstruct the inferior vena cava and/or other venous inflow. Additionally, the presence of the liver in the thoracic cavity may lead to impairment in the lymphatic flow leading to hydrothorax and lethal pulmonary hypoplasia ${ }^{[6,7]}$. Sydorak et al. ${ }^{[8]}$ speculated the cause of the hydrops is secondary to venous compression by herniated liver. Another possible cause reported by Narvey and Soni ${ }^{[9]}$ is the direct hepatic compression on the right and left atrium causing decrease in both systemic and pulmonary venous return and causing non-immune hydrops.

Burgos from the Congenital Diaphragmatic Study Group included 3754 infants reported no difference in gender rate, birth weight, gestational age at birth, delivery mood or the rates of associated major cardiac or chromosomal anomalies between RT-CDH and LT$\mathrm{CDH}^{[2,4,10]}$.

In a retrospective chart review of $330 \mathrm{CDH}$ cases, it was found that in comparison to LT-CDH, RT-CDH has stronger association with pulmonary morbidities secondary to severe pulmonary hypoplasia. Such morbidities include longer duration of nitric oxide therapy, increased requirement of tracheostomy, need for oxygen therapy at discharge, and increased chronic pulmonary hypertension with requirement for longterm sildenafil therapy all of which delays repair of the hernia $^{[3]}$.

Mortality rate reported to be either higher in RT sided defect ${ }^{[2]}$, or similar ${ }^{[3,4]}$ to the mortality rate in $\mathrm{LT}$ sided defect.

Our patient was diagnosed antenatally at 29 weeks of gestation to have RT-CDH associated with hydrops, born as a preterm, had severe pulmonary hypertension which delayed his operation to repair the diaphragmatic defect until day 24 of life which is consistent with another study ${ }^{[3]}$, oral feeding was started within three days post-operative which is significantly shorter than has been reported previously by Partridge et al. ${ }^{[3]}$. Patient was discharged home at age 63 days, which is consistent with the other report, on full oral feed and on no respiratory support.

\section{Conclusion}

In cases of RT-CDH associated with hydrops, prenatal diagnosis combined with optimum respiratory support postnatally in the absence of major congenital anomalies is considered a major contributing factor for survival. 


\section{Conflict of Interest}

The author has no conflict of interest.

\section{Disclosure}

The author did not receive any type of commercial support either in forms of compensation or financial for this report. The author has no financial interest in any of the products or devices, or drugs mentioned in this article.

\section{Ethical Approval}

Obtained.

\section{References}

[1] Langham MR Jr, Kays DW, Ledbetter DJ, Frentzen B, Sanford LL, Richards DS. Congenital diaphragmatic hernia. Epidemiology and outcome. Clin Perinatol 1996; 23(4): 671-688.

[2] Fisher J, Jefferson R, Arkovitz M, Stolar C. Redefining outcomes in right congenital diaphragmatic hernia. I Pediatr Surg 2008; 43(2): 373-379.

[3] Partridge EA, Peranteau WH, Herkert L, Rendon N, Smith $H$, Rintoul NE, Flake AW, Adzick NS, Hedrick HL. Right-versus left-sided congenital diaphragmatic hernia: a comparative outcomes analysis. J Pediatr Surg 2016; 51(6): 900-902.

[4] Beaumier CK, Beres AL, Puligandla PS, Skarsgard ED; Canadian Pediatric Surgery Network. Clinical characteristics and outcomes of patients with right congenital diaphragmatic hernia: A population-based study. J Pediatr Surg 2015; 50(5): 731-733.

[5] Duess J, Zani-Ruttenstock E, Garriboli M, Puri P, Pierro A, Hoellwarth M. Outcome of right-sided diaphragmatic hernia repair: a multicentre study. Pediatr Surg Int 2015; 31(5): 465-471.

[6] Yonekura T, Kubota A, Hoki M, Asano S, Nakayama T, Kato $\mathrm{M}$, Oyanagi $\mathrm{H}$. Intermittent obstruction of the inferior vena cava by congenital anteromedial diaphragmatic hernia: An extremely rare case of Budd-Chiari syndrome in an infant. Surgery 1998; 124(1): 109-111.

[7] Giacoia GP. Right-sided diaphragmatic hernia associated with superior vena cava syndrome. Am J Perinatol 1994; 11(2): 129-131.

[8] Sydorak RM, Goldstein R, Hirose S, Tsao K, Farmer DL, Lee $\mathrm{H}$, Harrison MR, Albanese CT. Congenital diaphragmatic hernia and hydrops: A lethal association? J Pediatr Surg 2002; 37(12): 1678-1680.

[9] Narvey M, Soni R. Hydrops fetalis due to direct hepatic compression of the right atrium in a newborn with right congenital diaphragmatic hernia. J Neonatal Biol 2016; 5(1): 1000206
[10] Burgos CM, Frenckner B, Luco M, Harting MT, Lally PA, Lally KP; Congenital Diaphragmatic Hernia Study Group. Right versus left congenital diaphragmatic hernia - What's the difference? J Pediatr Surg 2017: S0022-3468(17): 3064930648. 
Right Side Congenital Diaphragmatic Hernia and Hydrops: May Not Be Lethal M.Y. Bamehriz

\title{
فتق الحجاب الحاجز الخلقي للجهة اليمنى المصاحب لاستسقاء: قد لا بسبب الثو فُاة
}

\author{
مها يسلم احمد بامحرز

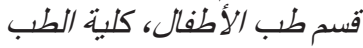 \\ جامعة الملك عبد العزيز \\ جدة ـ المملكة العربية السعودية
}

الكستخلص. فتق الحجاب الحاجز الخلقي للجهة اليمنى المصاحب للاستسقاء هي حالة نادرة لها تبعات غير حميدة. وها نحن نقوم بتسجيل الحالة والتي تم تتخيصها خلال فتره الحمل وقد خرج المريض من المستشفى في حالة جيدة. 